\title{
Fostering Social Connectedness in Educational Qualitative Research
}

\author{
Doreen Said Pace \\ Institute For Education, Martin Luther King Road, Pembroke PBK 1900, Malta \\ Ministry For Education, Floriana, Malta \\ * E-mail of the corresponding author: doreen.said.pace@ilearn.edu.mt
}

\begin{abstract}
This paper discusses the meaning and effect of social connectedness in the process of the research storytelling. It will start by arguing that the social aspect of the qualitative research is directly affected by the philosophical underpinnings of the researcher which, in turn, influences the paradigm tradition the research situates itself in. Following this debate, a research scenario will be presented where the reader will be taken on a journey from the issue, aims and purpose to the design, methodology, method and ethical considerations. This journey will highlight how the social constructionism theoretical framework permeates through all the decisions that have been made during the research design, implementation, analysis and the final stages.
\end{abstract}

Keywords: social constructionism, connections, collaboration, action research

DOI: $10.7176 / \mathrm{JEP} / 12-10-13$

Publication date: April $30^{\text {th }} 2021$

\section{Introduction}

This study was carried out in a Maltese state primary school context. Malta has three education sectors under the responsibility of the Ministry For Education (MFED), namely, the state, the non-state Secretariat For Catholic Education and the non-state Private Independent. The student cohort per group is of $60 \%, 30 \%$ and $10 \%$ respectively (National Statistics Office, 2018). Recent educational reforms across the sectors and cycles of education have been, and are still, taking place in shifting from prescriptive syllabi to a learning outcomes approach based with a more balanced assessment approach combination of on-going continuous and summative end-of-year assessment. Within this set of reforms, the change to the learning outcomes was preceded by a new national curriculum emphasizing on a student-centred approach whilst encouraging the use of assessment for learning (Ministry of Education and Employment, 2012). It is in this light that the research scenario has investigated the beliefs of prospective users of Afl. However, the aim of this paper is not the research itself but the degree and intersection of the social element within the entire research design.

\section{The Meaning of Social Connectedness}

"Social connectedness is an important predictor of health outcomes and plays a large role in the physical and mental health of an individual and a community" (Deitz et al., 2020: 1). It is thus important because it provides people with the emotional support, material help, and the information they need to thrive...hence crucial for the overall well-being (Full Frame Initiative, 2013). When people cannot connect to each other in person, other forms of connections are sought, and this has become especially evident in these unprecedented times of social restrictions. Individuals and communities are resorting to social media and virtual connections to discuss, debate, learn and even carry out research showing that the social dimension through which people communicate has been changed by both the progress and the contextual demands. Undoubtedly, what the people discuss and write about influences the audience, whoever that maybe, meaning that change is at least instigated by the multifaceted ways of coming together of people. In the teaching and learning sphere, the effect of the digital world necessitated the need for a new operating theory - connectivism - as the behaviorism, cognitivism and constructionism did not suffice the requirements of the teaching and learning modality through technology (Said Pace, 2020).

The effect of people's actions on the immediate environment is rooted in social constructionism where the subjects and objects are considered as partners (Crotty, 1998; Blaikie, 2000; Schwandt, 2000). An individual's and/or community's context provides an understanding into why that community holds such knowledge (Lincoln 
et al., 2011), hence explicates what that community holds particular beliefs that, in turn, shape what they know and practice (Said Pace, 2018). In constructionism, researchers have to be aware and thus state whether they subscribe to Piaget's (1971) or Vygotsky's (1978) notion of social construction because they differ in their emphasis between the individual's and group's effect on the immediate environment. Vygotsky places huge weight on the effect of the group's discourse within the community whereas Piaget takes a more individualistic stance related to the stages of development. Being a firm believer in the power of interpersonal skills, my view of how we come to know what we know aligns with Vygotsky's construction. Hence, I accept that professional and personal positionalities shape, and tries to reshape, the immediate operating environment meaning that their upholding can be justified by the circumstances that led them to it (Gray, 2013). Nonetheless, accepting does not mean that I must subscribe to what they uphold, but that I can empathize.

The impact of the nature of reality on the knowledge formation had been pointed out by Dewey (1930) who sustained that communities should not go into an "either-or" reality debate. Instead, the focus should be on how the new reality emanates from the educator's craft-knowledge (Russell, 2015). Understanding the educators' and/or the stakeholders' perspectives on an educational-related topic of inquiry for then to examine that situation and propose recommendations for amelioration is what most educational research is about. Doing so, necessitates that researchers have to get with human beings and into their world to find out about their interactions with the world (Windschitl, 2002). Consequently, familiarization with the context is imperative to not only understand but to interpret better their experiences (Said Pace, 2018). This is what interpretivism is about; getting "on the inside" of the field (Clough and Nutbrown, 2012: 64).

Interpretivism can manifest itself through three possible dimensions - empathy, phenomenology and language frames (Schwandt, 2000). With empathy, researchers try to look at the situation from the participants' lens by entering their shoes to experience the world as they would be doing. In phenomenology, researchers try to understand the phenomenon under study from the lived experiences through the language discourse adopted by the practitioners. Being in the field does not strip researchers from their professional and personal portfolios implying that as much as they try to be objective in their interpretations, they can never be completely objective, and this is an acknowledged and accepted fact in research (Ormston et al., 2013). What is important is that such positionality is recognized. If a researcher holds a position of professional power, the data collected can be questioned unless measures would have been taken to mitigate it. A case in point is the study by Said Pace (2018) who opted out of classroom observations to avoid professional conflict. Nonetheless, the same work had recognized this measure as one of the limitations of that study, but it had to be taken to enhance the credibility of the study since an "insider research" was being carried out (Sikes and Potts, 2008: 3).

The above philosophical backdrop has underpinned the qualitative research design and the subsequent process of the following research about the teachers' beliefs and practices on formative assessment in one Maltese state college.

\subsection{Research Rationale: Issues, Aims and Purpose}

Head of Department for assessment was my professional role prior to, and during, the research which constituted in supporting schools in the introduction, development and sustainability of formative assessment. It was the daily reflexive process within this remit that triggered the need for further study into how formative assessment or what locally is being considered as Assessment for Learning (AfL) was being perceived as empirical experience led me to the hunch that it was being perceived as an add-on adopted through a have-to approach.

Self-reflection is one of the hallmarks of leadership as it allows the opportunity to think about the challenges being encountered in the work environment - challenges that would hinder the work (Sudmann, 2016). Such self-confrontation led to the inquiry about whether a collaborative action research approach could assist and facilitate the implementation of formative assessment by prospective users. The process of embarking on a reallife issue from the social environment had already been identified by Crotty (1998: 13) when argued that "...it is hardly the case that researchers embark on a piece of study from their epistemological stance..." This does not mean that one's ways of knowing will be ignored, but it reveals the importance of the social connectedness for then to consider your self-awareness that would shape the study.

The aim of the study that will be discussed was to explore and examine the prospective AfL users' beliefs about formative assessment for then to not only create new knowledge for the local context but also to enrich the international literature, inform policymakers and the educational institutions' providers to better the local provision of formative assessment. 


\subsection{Overarching Research Question}

The study was guided by the below overarching question and the subsequent set of subsidiary questions.

- How can collaborative action research (CAR) contribute to the prospective class practitioners' beliefs and practices about Afl?

- What are the class practitioners' beliefs prior to CAR?

- What are the class practitioners' beliefs following the CAR experience?

- What are the turning points, if any, for change in the beliefs and practices?

\section{Research Design}

Designing research is synonym to an architect designing a blueprint for a house (De Vaus, 2001); the plan shaping the entire study (Clough and Nutbrown, 2012; Creswell, 2013). At the initial stage, the planner needs to be aware of the intended audience, what data is needed and what will be done with it. Answering these questions help researchers to structure the inquiry that would get them to the research questions (De Vaus, 2001). It can be argued that a sound research design attends to the "logic of appropriateness" (Greener, 2011: 2); shows the fitness for purpose advocated by Cohen et al. (2018) and more importantly, ascertains methodological congruence (Richards and Morse, 2012).

Figure 1 illustrates the research design adopted for this study. A qualitative research was the fittest for the purpose as it allowed the researcher to delve deeper into the problem while exploring, examining and interpreting a situation (Creswell, 2013). It was also interpretive because as Gray (2013: 37) holds "interpretivism seeks to explore the people's experiences and their views or perspectives of these experiences." The relation between qualitative research methods, interpretivism and social connectedness is reflected Lichtman's (2013: 10) working definition who states that:

Qualitative research is a way to study the social interactions of humans in naturally occurring situations where the researcher plays a critical role in the process by gathering data and making sense of or interpreting the phenomena that are observed and revealed.

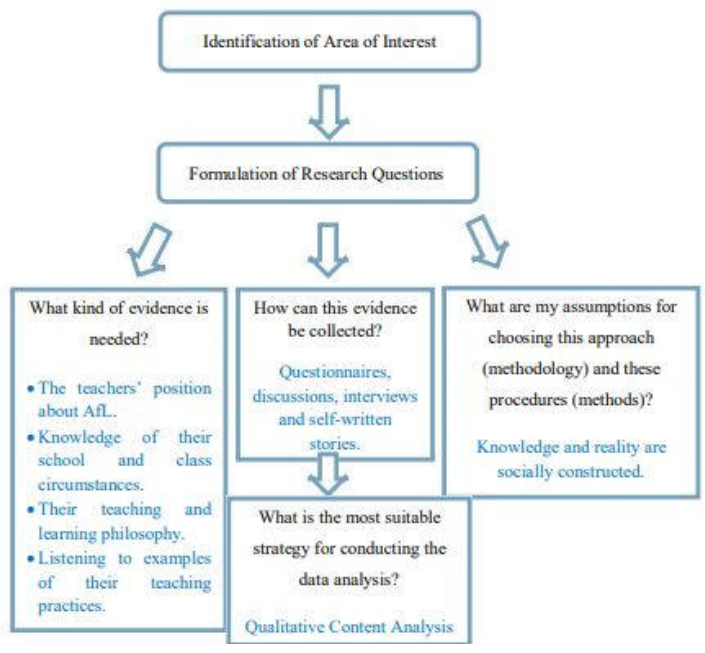

Figure 1: Research Design Flow Chart

Source: Said Pace (2018, p. 101) in Assessment for Learning in one Maltese State College

\subsection{Research Methodology}

Concerned about non-using the research participants as a means to my end, a methodology that would provide a mutual benefit - research data for me and professional growth for the participants - was opted for. Collaborative Action Research (CAR) does just that because "it provides learning opportunities that create changes in teachers' 
disposition about teaching and learning, leading to changes in classroom practice and resulting in improved student achievement" (Bleicher, 2014: 216-217). Furthermore, since CAR is a sub-branch of action research, it leverages the teachers' knowledge to research data, (Dewey, 1930), while providing the space for reflection on, and in, one's practice, a much needed practice by professionals who are not academic researchers (Adelman, 1993). Having reflective practitioners would facilitate the bridging between theory and practice especially on curriculum matters and student learning (Stenhouse, 1975).

My working definition of CAR is that of a collaborative quest on a multi-social level to not only improve a situation but at the same time, it empowers the members or 'actors' of that situation to elevate their craft knowledge to come to consider it as worthwhile knowledge that can be celebrated and shared with others (Said Pace, 2018). The questions they ask - How do I improve the situation? and How do we ameliorate the situation? (Ghaye et al., 2008), will be important and of interest to others implying that the CAR is a research process imbued by a high degree of social participation and connectedness (Riel, 2017; McTaggart, 1989). This social exercise emphasises the equity principle meaning that there is not space for an authoritarian role (Dickson and Green, 2001) because everyone's expertise is valued (Reason and Bradbury, 2001) and consequently, there is greater ownership of the outcomes (Brydon-Miller et al., 2003). Moving from knowledge about a specific situation to a general approach by the year group or the school requires an inductive approach thus respecting one's valuable input.

The participant's unfamiliarity with such research practice created a challenge to balance out our roles as they looked up to me to be told what to do when I wanted them to embrace the notion of control over their own situation (Wamba, 2014). Due to this cultural issue, I had to take a leading role at the beginning for then to gradually relinquish that 'power'. It was not the intention to dictate but to explore a situation in a healthy atmosphere (Messner and Rauch, 1995; Postholm and Skrøvset, 2013). Another challenge was differentiating between CAR and participatory action research (PAR) where one of the distinguishing factor is the role taken up by the guiding researcher - in the former, the researcher is carrying out a level of action research whereas in the latter, it is just facilitation.

Practitioners can engage in various levels of action research - first order, when class educators are working on an own situation; second order, when collaborating with fellows on a shared problem; and third, when sharing their improvements with others. Thus, the triad levels of action research move from the individual effect within one's context to the extended effect which can be the year group, the school, the college and/or nationally. Starting from your own change is similar to investing in one's human capital which when then effects your professional social circle, the snowballing effect creates the social capital dimension (Hargreaves and Fullan, 2012).

In adopting Wenger's (1998) suggestion for collaborating with teachers by transferring my role to "an insider rather than a spectator" (McNiff, 2017: 10), they looked at the research as a means of support instead of an invasion into their professional world (Cain and Harris, 2013). It can be safely said that this intent has been reached as per the evidence submitted by one of the co-action researchers:

I am not taking it as if I am doing you a particular favour. Instead, you are doing it to me as I am really learning. I really work hard and when I

find something effective...I feel that you are equipping me with an extremely powerful and helpful tool...I really feel honoured and thank you on behalf of the learners as they are really benefiting.

Source: Said Pace (2018). Assessment for Learning in one Maltese State College, p. 308

Social connectedness has not only been included in the methodological process but also in the data instruments as will be discussed next.

\subsection{Data Collection Methods: Pros and Cons}

Various data gathering instruments were used for triangulation purposes and to increase the trustworthiness of the study. The methods included group discussion meetings, record-keeping booklet, 1-1 feedback sessions, focus groups with the students and self-written accounts. Such repertoire of methods allowed for the possible congruence in the verification of data (Creswell and Miller, 2000). Thick descriptions of each data enhanced the credibility of the study (Guba, 2004). 
The group discussion meetings created a safety net for the co-action researchers where to exchange their ideas and to debate about their 'problem' in a trusting environment (Birenbaum et al., 2009).

The record-keeping booklet acted like a personal diary in which the instant reflections were jotted to ensure that none of the important data is lost (Hyland, 2000; Cohen et al., 2011). It was also a reference tool for the group discussions and the one-one feedback sessions. The latter provided an additional opportunity for the coresearchers to discuss with the guiding researcher issues that they were not yet comfortable to talk about in the group (Seidman, 2013).

The purpose of the semi-structured interviews was to "understand the lived experience of others and their sensemaking of that activity" (Seidman, 2013: 9). They were unstructured to allow the possibility of prompting and further probing according to the responses submitted. Interview questions were sent one week beforehand and before the actual meeting, the participant's permission was sought for audio-recording the session.

The students' focus groups aimed at giving a voice to the ultimate beneficiaries of the assessment process to explore how they perceived the experience for then to recount their stories - a first for the Maltese context. Participants of the focus groups involved only those students whose parents had consented to their involvement in the research.

The teacher's self-written stories offered a significant degree of originality, authenticity and veracity as they were freely written by the actors themselves. Therefore, it was a personal and practical recount free from the researcher's bias (Connelly and Clandinin, 1990).

All the data collected were compiled in one file which was shared back with the participants for their verification and consent on the data that they wanted to be analysed. Such option was not only very democratic but ensured high ethical standards in respect to the teachers' knowledge.

If I had to choose the most preferred method from the above list, it would be the semi-structured interviews as they allowed a professional and yet private space for dialogue with the co-researchers. In this dialogue, further insights could be gathered through the prompting leads from the co-researcher's responses. Although anonymity cannot be kept, confidentiality can, and should, be. Interview is a great method for a social encounter that should be based on mutual trust as otherwise honesty can be questioned, jeopardizing the data.

\subsection{Research Participants' Recruitment, Access and Ethical Issues}

Access to the research fields was granted by the Directorate for Research and Lifelong Learning, as the research was carried out in the state sector only, following the submission of all the required documentation. Further permissions were sought from the Head of College Network (HOCN), the Head of School (HOS) and the teachers themselves to show their interest or to state otherwise. An information session was held with all the teachers during their non-contact time during which a verbal explanation of the research was given, the information letter was distributed, and a one-week window frame provided enough thinking time for the teachers. The information letter and consent forms explained the rationale and purpose of the research together with their rights to withdraw at any time and to have their identity protected even when the research was over. Data would only be used for the thesis and subsequent publications in scholarly peer-reviewed journals.

The volunteer co-researcher's, within a purposive school selection, sampling was based on the need to have had established a good trusting relationship, which, in this case, I had as I had worked at the same school for three years in the role of an Inclusion Coordinator. Hence, certain groundwork was already in place. Nonetheless, this did not place me at an advantage as three teachers from a complement of nineteen came forward to participate while five felt that they had to justify their non-acceptance even though they were not obliged to do so.

Given the insider research role that I had, class observations were opted out so as to avoid professional conflict in that teachers might think that the observation outcomes might impinge on their teaching performance management. Although this was a limitation of the study, it was more ethical to do so.

Ultimately, even in ethics there is social connectedness as "research is a political process because it brings in the researcher's own constructs ...that affect their behavior and such demeanor does not entitle them to override other considerations by ignoring the scientific rules of the research conduct" (Guthrie, 2010: 7)

\subsection{Data Storage and Ownership}

The information letter stated that data would be stored in a safe place which could be accessed only by the 
researcher. Data would be destroyed after a year.

Ownership of the raw data remained the exclusivity of the participants, however, the analysis of that data and the findings stemming from it were owned by the researcher. This shared ownership enhanced further the social connectedness that had been established during the researcher to post research relationship. In fact, a year after the research completion, I had the opportunity to visit again the school and one of the participants remarked that when she listens, reads or sees the term Assessment for Learning (AfL), she recalls our study, which to me is very positive because the research process and outcome remained relevant for the participant.

\section{Conclusion}

A distinguishing factor of qualitative research is the being with the research participants rather than the carrying of the research on them. Such stance entails high interpersonal skills which are shaped by the researcher's beliefs about how the social mingling and context effect the creation and existence of knowledge and reality. This philosophical awareness has started the discussion in this essay which then led to the research issue under exploration, an issue which emanated from professional social encounters. The research purpose - to understand and explore - justified the need for interpretation and for choosing a qualitative research method which, in turn, has shaped the design, the methodology and the methods so that an alignment between them could be ensured. Recruitment, access and ethical considerations have also taken account of the importance of the social element in research and in all the stages, a democratic approach was adopted.

\section{References}

Adelman C. (1993) Kurt Lewin and the Origins of Action Research. Educational Action Research 1: 7-24.

Birenbaum M, Kimron H, Shilton H, et al. (2009) Cycles of inquiry: Formative assessment in service of learning in classrooms and in school-based professional communities. Studies in Educational Evaluation 35: 130-149.

Blaikie N. (2000) Strategies for Answering Research Questions. In: Press P (ed) Designing Social Research. Oxford, UK: Blackwell, 85-127.

Bleicher RE. (2014) A collaborative action research approach to professional learning. Professional development in education 40: 802-821.

Brydon-Miller M, Greenwood D and Maguire P. (2003) Why Action Research? Action Research 1: 9-28.

Cain T and Harris R. (2013) Teachers' action research in a culture of performativity. Educational Action Research 21: 343-358.

Clough P and Nutbrown C. (2012) A Student's Guide to Methodology: Sage Publications.

Cohen L, Manion L and Morrison K. (2011) Research Methods in Education, London: Routledge.

Cohen L, Manion L and Morrison K. (2018) Research methods in education (eight edition): New York: Routledge Palmer.

Connelly FM and Clandinin DJ. (1990) Stories of Experience and Narrative Inquiry. Educational Researcher 19: 2-14.

Creswell JW. (2013) Qualitative inquiry and research design: Choosing among five approaches: Sage.

Creswell JW and Miller DL. (2000) Determining Validity in Qualitative Inquiry. THEORY INTO PRACTICE 39.

Crotty M. (1998) The foundations of social research: Meaning and perspective in the research process: Sage.

De Vaus DA. (2001) Research design in social research: Sage.

Deitz RL, Hellerstein LH, St. George SM, et al. (2020) A qualitative study of social connectedness and its relationship to community health programs in rural Chiapas, Mexico. BMC Public Health 20: 1-10.

Dewey J. (1930) The quest for certainty: A study of the relation of knowledge and action. The Journal of Philosophy 27: 14-25.

Dickson G and Green KL. (2001) The external researcher in participatory action research. Educational Action Research 9: 243-260.

Full Frame Initiative. (2013) Five domains of wellbeing: Social connectedness. Available at: www.fullframeinitiative.org.

Ghaye T, Melander-Wikman A, Kisare M, et al. (2008) Participatory and appreciative action and reflection (PAAR) - democratizing reflective practices. Reflective Practice 9: 361-397.

Gray DE. (2013) Doing research in the real world: Sage.

Greener I. (2011) Designing social research: A guide for the bewildered: Sage Publications.

Guba EG. (2004) Authenticity Criteria. In: Lewis-Beck MS, Bryman A and Futing Liao T (eds) The SAGE Encyclopedia of Social Science Research Methods. Sage Publications, Inc. 
Guthrie G. (2010) Research Ethics. Basic research methods: An entry to social science research. New Delhi: SAGE Publications India, 15-24.

Hargreaves A and Fullan M. (2012) Professional capital: Transforming teaching in every school: Teachers College Press.

Hyland Á. (2000) Multiple Intelligences, Curriculum and Assessment Project: Final Report: NAIRTL.

Lichtman M. (2013) Qualitative research for the social sciences: SAGE publications.

Lincoln YS, Lynham SA and Guba EG. (2011) Paradigmatic controversies, contradictions, and emerging confluences, revisited. The Sage handbook of qualitative research 4: 97-128.

McNiff J. (2017) Action Research: All You Need to Know: SAGE.

McTaggart R. (1989) 16 Tenets of Participatory Action Research. Available at: http://www.caledonia.org.uk/par.htm.

Messner E and Rauch F. (1995) Dilemmas of Facilitating Action Research. Educational Action Research 3: 4153.

Ministry of Education and Employment. (2012) A National Curriculum Framework for All.

National Statistics Office. (2018) Statistics on Pre-Primary, Primary and Secondary Formal Education. Valletta, 63.

Ormston R, Liz S, Matt B, et al. (2013) Qualitative a Guide for Social Science Students and researchers. 0-25.

Piaget J. (1971) The theory of stages in cognitive development.

Postholm MB and Skrøvset S. (2013) The researcher reflecting on her own role during action research. Educational Action Research 21: 506-518.

Reason P and Bradbury H. (2001) Handbook of action research: Participative inquiry and practice: Sage.

Richards L and Morse JM. (2012) Readme first for a user's guide to qualitative methods: Sage.

Riel M. (2017) Collaborative Action Research Query. In: Said Pace D (ed) Email Communication ed.

Russell T. (2015) Teacher Craft Knowledge. In: Gunstone R (ed) Encyclopedia of Science Education. Dordrecht: Springer Netherlands, 1021-1022.

Said Pace D. (2018) Assessment for Learning (AfL) in one Maltese State College. University of Sheffield.

Said Pace D. (2020) The use of Formative Assessment (FA) in Online Teaching and Learning during the COVID-19 compulsory education school closure: the Maltese experience. Malta Review of Educational Research 14: 30.

Schwandt TA. (2000) Three epistemological stances for qualitative inquiry. Handbook of qualitative research 2: 189-213.

Seidman I. (2013) Interviewing as qualitative research: A guide for researchers in education and the social sciences: Teachers college press.

Sikes P and Potts A. (2008) Introuction: What are we talking about? And why? In: Sikes P and Potts A (eds) Researching Education from the Inside: Investigations from within. London, USA and Canada: Routledge, 187.

Stenhouse L. (1975) An introduction to curriculum research and development: Heinemann London.

Sudmann L. (2016) Great leadership starts with self-leadership. TedxTalks. TED Conferences.

Vygotsky LS. (1978) Mind in society: The development of higher mental process: Cambridge, MA: Harvard University Press.

Wamba NG. (2014) Participatory action research for school improvement: the Kwithu project: SAGE.

Wenger E. (1998) Communities of Practice: Learning as a Social System. Systems Thinker 9: 10.

Windschitl M. (2002) Framing Constructivism in Practice as the Negotiation of Dilemmas: An Analysis of the Conceptual, Pedagogical, Cultural, and Political Challenges Facing Teachers. Review of Educational Research 72: 131-175.

Dr Doreen Said Pace is accredited with the Practitioner Status of the Association for Educational Assessment Europe. She been in the field of education for the past twenty-two years where she held various roles including Education Officer for Curriculum and Inclusion, Inclusion Coordinator duties, Head of Department

(Assessment), Early Intervention Teacher and a class teacher. She is also a visiting lecturer and dissertation supervisor with the Institute for Education and the University of Malta. She has been part of interviewing boards as well as national working groups. She has also published articles in international journal and has chapters in edited books and participated in national and international conferences.

Acknowledgement - Special thanks go to the participants of the study with whom it was possible to build a positive and strong connection following nine-months of research. 